\title{
The relationship of thermospheric density anomaly with electron temperature, small-scale FAC, and ion up-flow in the cusp region, as observed by CHAMP and DMSP satellites
}

\author{
G. N. Kervalishvili and H. Lühr \\ Helmholtz Centre Potsdam, GFZ German Research Centre for Geosciences, Telegrafenberg, 14473 Potsdam, Germany
}

Correspondence to: G. N. Kervalishvili (guram.kervalishvili@gfz-potsdam.de)

Received: 27 September 2012 - Revised: 4 March 2013 - Accepted: 5 March 2013 - Published: 20 March 2013

\begin{abstract}
We present in a statistical study a comparison of thermospheric mass density enhancements $\left(\rho_{\text {rel }}\right)$ with electron temperature $\left(T_{\mathrm{e}}\right)$, small-scale field-aligned currents (SSFACs), and vertical ion velocity $\left(V_{\mathrm{z}}\right)$ at high latitudes around noon magnetic local time (MLT). Satellite data from CHAMP (CHAllenging Minisatellite Payload) and DMSP (Defense Meteorological Satellite Program) sampling the Northern Hemisphere during the years 2002-2005 are used. In a first step we investigate the distribution of the measured quantities in a magnetic latitude (MLat) versus MLT frame. All considered variables exhibit prominent peak amplitudes in the cusp region. A superposed epoch analysis was performed to examine causal relationship between the quantities. The occurrence of a thermospheric relative mass density anomaly, $\rho_{\text {rel }}>1.2$, in the cusp region is defining an event. The location of the density peak is taken as a reference latitude $\left(\triangle \mathrm{MLat}=0^{\circ}\right)$. Interestingly, all the considered quantities, SSFACs, $T_{\mathrm{e}}$, and $V_{\mathrm{z}}$ are co-located with the density anomaly. The amplitudes of the peaks exhibit different characters of seasonal variation. The average relative density enhancement of the more prominent density peaks considered in this study amounts to 1.33 during all seasons. As expected, SSFACs are largest in summer with average amplitudes equal to $2.56 \mu \mathrm{A} \mathrm{m}^{-2}$, decaying to $2.00 \mu \mathrm{A} \mathrm{m}^{-2}$ in winter. The event related enhancements of $T_{\mathrm{e}}$ and $V_{\mathrm{z}}$ are both largest in winter $\left(\Delta T_{\mathrm{e}}=730 \mathrm{~K}, V_{\mathrm{z}}=136 \mathrm{~m} \mathrm{~s}^{-1}\right)$ and smallest in summer $\left(\Delta T_{\mathrm{e}}=377 \mathrm{~K}, V_{\mathrm{z}}=57 \mathrm{~m} \mathrm{~s}^{-1}\right.$. Based on the similarity of the seasonal behaviour we suggest a close relationship between these two quantities. A correlation analysis supports a linear relation with a high coefficient greater than or equal to 0.93 , irrespective of season. Our preferred explanation is that dayside reconnection fuels Joule heating of
\end{abstract}

the thermosphere causing air upwelling and at the same time heating of the electron gas that pulls up ions along affected flux tubes.

Keywords. Ionosphere (Particle precipitation; Polar ionosphere) - Magnetospheric physics (Magnetosphereionosphere interactions)

\section{Introduction}

The thermosphere is part of the upper atmosphere and located in the altitude range between about $90 \mathrm{~km}$ and $1000 \mathrm{~km}$. We note that the exobase is located near $500 \mathrm{~km}$ altitude. The thermospheric dynamics is affected by many different complex processes and has a large variability in temperature and density depending upon solar extreme ultraviolet (EUV) radiation and geomagnetic disturbances. Its dynamics and response to solar activity, including ionosphere-thermosphere coupling, has been studied theoretically, experimentally, and observationally for decades (e.g. Roble, 1983; Prölss, 1997). The influence caused by the dissipation of the solar wind energy on the upper atmosphere was outlined in a comprehensive review by Prölss (2011). In particular, the morphology and the dependence on the level of geomagnetic activity of density perturbations were presented. Also perturbations of air composition were investigated. Prölss (2011) indicated a strong correlation of density perturbations on the AE (auroral electrojet) index and weaker on the Dst (disturbance storm time) index and the interplanetary electric field at high latitudes.

Understanding the variability of the neutral mass density and its relationship to upwelling ions in the high-latitude 
upper thermosphere is a crucial part of this research. However, the study of the neutral mass component was often limited or not taken into account because of a lack of suitable in situ measurements. Since, 2000 with the launch of the CHAMP (CHAllenging Minisatellite Payload) and later the GRACE (Gravity Recovery And Climate Experiment) satellites it became possible to study thermospheric density in detail (Lühr et al., 2004; Liu et al., 2005; Schlegel et al., 2005; Bruinsma et al., 2006; Liu et al., 2011). Unfortunately, GRACE (Tapley et al., 2004) does not provide electrodynamic quantities, e.g. field-aligned currents (FACs) and electron temperature data; however, CHAMP (Reigber et al., 2002) gives us a unique possibility to investigate these and neutral thermospheric density data simultaneously at some $400 \mathrm{~km}$ altitude above the ground.

The CHAMP mission made the new and surprising observation of localized peaks in thermospheric mass density measurements. These air drag peaks were observed in both hemispheres. Lühr et al. (2004) were the first to empirically investigate these thermospheric density anomalies occurring within the polar cusp region in some detail. The polar cusp is the dayside funnel-shaped region in both hemispheres, where magnetosheath plasma has near-direct access to the lower altitude ionosphere (Russell, 2000). Also, the simultaneous occurrences of neutral density anomalies and ionospheric currents were observed in both hemispheres. Density anomalies are mostly accompanied by intense small-scale field-aligned currents (SSFACs); therefore, Lühr et al. (2004) suggested Joule heating associated with intense SSFACs as a primary source for the neutral mass density upwelling.

Demars and Schunk (2007), motivated by the density enhancements presented by Lühr et al. (2004) used a high-resolution model of the global thermosphere (Ma and Schunk, 1995) and sought to reproduce the density anomaly in the northern dayside cusp region. Their model used an ionneutral frictional heating approach, which led to the thermospheric upwelling. The authors had to increase the heating factor artificially by a nonrealistic factor of 110 in order to reproduce a local doubling of the thermospheric mass density at dayside polar latitudes. Their aim was to investigate the response of the neutral density on the heating rather than to study the heating mechanism itself.

Clemmons et al. (2008) presented thermospheric density enhancements in the southern cusp region observed by the Streak mission in the altitude range of $123-325 \mathrm{~km}$. The Streak mission (Clemmons et al., 2009) was accomplished during a ten month period in 2005-2006. Measurements made by this mission, which has a lower altitude than CHAMP (about $150 \mathrm{~km}$ ), showed density depletions rather than enhancements, as observed by CHAMP (Lühr et al., 2004; Liu et al., 2005). Nevertheless, these observations (Clemmons et al., 2008) were described as complementary to those of CHAMP and the differences were interpreted as an altitude effect. Clemmons et al. (2008) explained this effect by the precipitation of soft particles, which heat the thermo- sphere in different ways below and above $250 \mathrm{~km}$ altitude. Therefore, Streak is expected to observe very little density increase. Because of this difference in heating, Clemmons et al. (2008) interpreted the relative density depletions as counter-parts to enhancements in adjacent regions. The authors proposed a direct heating mechanism, caused by the cusp precipitation, in order to explain density enhancements for both altitudes.

Prölss (2008) has studied perturbations of the upper atmosphere using the DE-2 satellite (Hoffman and Schmerling, 1981) observations. Additionally the relationship between density changes, temperature changes, and ion velocity in the cleft region were investigated. The unexpected decrease of thermospheric mass density (observed by DE-2 at about $350 \mathrm{~km}$ altitude) was explained by the heating of the lower thermosphere, which creates divergent winds that reduce the mass density locally. To explain the density enhancements observed by CHAMP the author suggested an altitude dependent mass density perturbation with a transition height between 300 and $400 \mathrm{~km}$ above which the temperature effect causes a density enhancement. Earlier, Prölss (2006) had reported significant enhancements of the electron temperature in the upper cusp-related ionosphere. Soft electron precipitation and heat conduction were suggested as controlling parameters depending on geomagnetic activity level and seasonal variations.

Rentz and Lühr (2008), motivated by the above discussed open issues, performed a systematic statistical analysis of the cusp-related density anomalies based on CHAMP observations for the years 2002-2005. The average density enhancement distribution for both hemispheres is considered only in the dayside auroral region, which covers the local time sector 08:00-16:00 $\mathrm{h}$ in MLT and the latitude range of 60$80^{\circ}$ MLat. Also geomagnetic storms were excluded from the presented analysis. It was shown that the magnitude of the yearly averaged density enhancement decreases with the reduction of the solar EUV flux level. It was also identified that the solar wind and interplanetary magnetic field are parameters that play a significant role for the formation of density anomalies. Enhancements of the merging electric field were observed about one hour before the anomaly detection. Rentz and Lühr (2008) suggested Joule heating as the most favourable driving mechanism for the formation of the density anomalies, where together with SSFACs the particle precipitation was suggested as an essential part of the energy deposition mechanism.

Lühr and Marker (2013) suggested an explanation for the occurrence of prominent mass density peaks in association with the ionospheric cusp, which is based on particle precipitation. Comparisons of DMSP particle measurements with the FAC estimates from the CHAMP and Ørsted satellites made by Watermann et al. (2009) during the SIRCUS (Satellite and Incoherent scatter Radar Cusp Studies) campaign showed that high fluxes of cusp-type particle precipitation are commonly accompanied by intense SSFACs. Therefore, 
the intense precipitation of low energy particles was regarded as the key process for controlling the location of the anomaly. Rentz and Lühr (2008) and Lühr et al. (2012) showed a strong dependence of the anomaly amplitude observed by CHAMP on the merging electric field, which can be regarded as a proxy for both the reconnection rate and the cross-polar cap potential.

Liu et al. (2010) in contrast to Rentz and Lühr (2008) studied density anomalies only during geomagnetic storms for the same time period (2002-2005). During this $4 \mathrm{yr}$ period about 30 storm events were considered with Dst $<-100 \mathrm{nT}$. A statistical analysis showed that the anomalies have sizes of $500-1500 \mathrm{~km}$ and dwell-times of less than $1.5 \mathrm{~h}$. Ion up-flow was suggested as a possible driving mechanism for thermospheric upwelling at high latitudes.

Burchill et al. (2010) investigated the relationship between ion up-flow and precipitating magnetosheath electron energy flux based on observations delivered by the Cusp2002 sounding rocket and ground-based radars (Pfaff et al., 2004). A mechanism was suggested for ion acceleration that emerged from the relationship between ion up-flow and electron energy flux. According to this mechanism the parallel electric fields that are established by the soft electron participation determine the ions acceleration.

Sadler et al. (2012) suggested a multi-step mechanism (soft electron precipitation in cooperation with ion up-flow) for the thermospheric neutral density enhancements above the F-region observed by the CHAMP satellite. According to these authors the charge imbalance, which is established by the expanding electron gas heated by the soft electron precipitation, pulls ions upward and then neutrals are dragged upwards by the momentum carried by the up-flowing ions.

Of particular interest for our investigation are the density anomalies and their relationship to the electron temperature, SSFACs, and upwelling ions occurring at high latitudes in the Northern Hemisphere. This paper provides the first detailed comparison of CHAMP (neutral density, electron temperature, SSFACs) and DMSP (ion vertical velocity) satellite observations, which have been made during $4 \mathrm{yr}$ of continuous measurements, 2002 to 2006 . In order to represent the influence of different atmospheric conditions, the obtained results are sorted into three local seasons (winter, combined equinoxes, summer).

Section 2 introduces the satellites used and processing steps applied to the given data set. Section 3 presents a statistical analysis of the density anomaly, electron temperature, SSFAC intensity, and ion vertical drift. A systematic survey of the data set based on a binning approach and the superposed epoch analysis (SEA) are presented in Sects. 3.2 and 3.3, respectively. There follows a correlation analysis between electron temperature and vertical ion drift variations (Sect. 3.4). In Sect. 4 different density enhancement scenarios are discussed. Finally, the main results of our study are summarized in Sect. 5.

\section{Data set and observations}

The data sets used here are from the CHAllenging Minisatellite Payload (CHAMP) satellite and Defense Meteorological Satellite Program (DMSP) F13 and F15 satellites. The observations presented in this study were sampled by the CHAMP satellite from March 2002 to March 2006 and by the DMSP F13 and F15 satellites from March 2002 to December 2005 in the Northern Hemisphere. The magnetic coordinates MLat and MLT used in this paper are based on the Apex coordinate system as described by Richmond (1995). Of interest for this study are the relative enhancement of the thermospheric mass density, the SSFAC intensity, electron temperature, and ion vertical drift. The data acquisition techniques will be described in the following subsections for each satellite separately.

\subsection{CHAMP satellite data}

CHAMP is a German satellite mission for geoscientific and atmospheric research, which was launched in July 2000 into a circular, near-polar orbit $\left(87.2^{\circ}\right.$ inclination $)$ at $460 \mathrm{~km}$ altitude (Reigber et al., 2002) and continued to function until September 2010. The satellite provides an excellent latitudinal coverage of polar regions. Due to the given inclination it takes eleven days for the orbital plane to sample one hour of local time. Therefore it takes about 130 days to pass through all local times when combining ascending and descending orbital arcs. The CHAMP scientific instruments, among others are, a tri-axial accelerometer, a vector magnetometer, and a planar Langmuir probe (PLP).

The tri-axial accelerometer data with time resolution of $10 \mathrm{~s}$ (equivalent to a sampling distance of $\sim 76 \mathrm{~km}$ ) are used to calculate the thermospheric mass density. The basic equation of the acceleration (deceleration) produced by the air drag can be expressed as

$\boldsymbol{a}=\frac{\boldsymbol{C}_{\mathrm{d}} A_{\mathrm{eff}}}{2 m} \rho v^{2}$,

where $\boldsymbol{a}$ is the measured acceleration (deceleration), $\boldsymbol{C}_{\mathrm{d}}$ is the drag coefficient vector with different values for alongtrack and cross-track directions, $A_{\text {eff }}$ is the effective crosssectional area in the ram direction, $m$ is the satellite mass ( $m \sim 500 \mathrm{~kg}$ ), $\rho$ is the thermospheric mass density, and $v$ is the total speed of the satellite. The thermospheric mass density $\rho$ can be solved from Eq. (1), because all other quantities are known or measured (Doornbos at al., 2010),

$\rho=\frac{2 m}{C_{\mathrm{d}} A_{\mathrm{eff}} v^{2}} \boldsymbol{a} \cdot \boldsymbol{v}$,

where $v$ is the unit vector for velocity in the ram direction.

The FAC density is derived from the CHAMP magnetic field measurements (Wang et al., 2005; Rother et al., 2007). The standard approach for deriving FACs from single satellite observations (Lühr at al., 1996) is based on the AmpereMaxwell law 


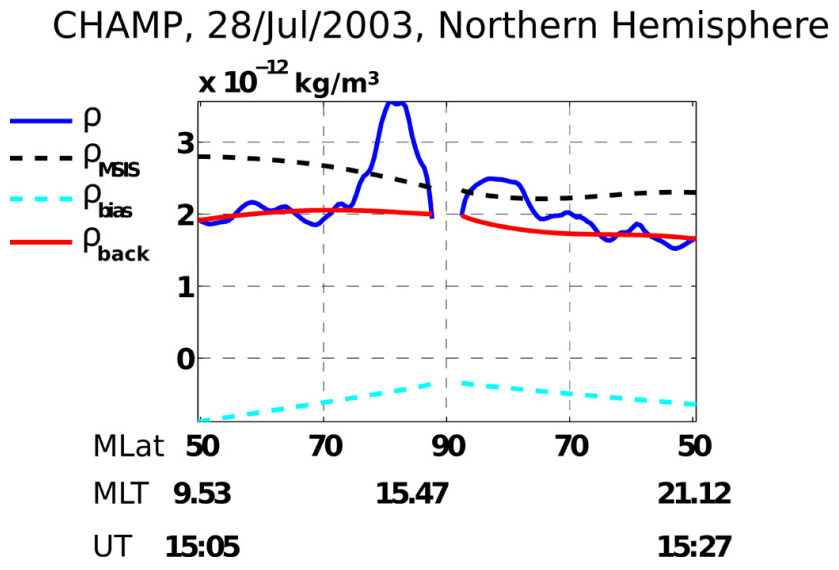

Fig. 1. Example for the background density and relative density enhancement determination procedures. The blue line indicates density from CHAMP data, the dashed black corresponding model density from NRLMSIS-00, the dashed cyan the linear bias function, and the red line the calculated background $\rho_{\text {back }}=\rho_{\text {MSIS }}+\rho_{\text {bias }}$.

$\boldsymbol{j}=\frac{1}{\mu_{0}} \nabla \times \boldsymbol{B}$,

and applied to satellite data

$j_{\mathrm{z}}=\frac{1}{\mu_{0} v_{\mathrm{x}}} \frac{\partial B_{\mathrm{y}}}{\partial t}$.

Here $\mu_{0}$ is the vacuum permeability, $v_{\mathrm{x}}$ is the velocity perpendicular to the current sheet, and $B_{\mathrm{y}}$ is the magnetic component parallel to the current sheet in the projected xy plane. The SSFAC densities used here are calculated at a rate of $1 \mathrm{~Hz}$ and have a spatial resolution of $\sim 7.6 \mathrm{~km}$. The additional CHAMP observation considered is the electron temperature derived from the PLP measurements with a time resolution of $15 \mathrm{~s}$ (Rother et al., 2010). This corresponds to a spatial resolution of $\sim 115 \mathrm{~km}$.

\subsection{DMSP F13 and F15 satellite data}

DMSP is a long-term operational meteorological, oceanographic, and solar-terrestrial physics program of the US DoD (Department of Defense). The DMSP F13 and F15 satellites were launched in March 1995 and in December 1999, respectively, into circular, Sun-synchronous, near-polar orbits (98 inclination) at $840 \mathrm{~km}$ altitude and continue to function to present. Both satellites have an orbital period of $\sim 102 \mathrm{~min}$ and fixed local times with F13 in a roughly dawn-dusk orientation and F15 in the 09:00-21:00 h local time sector. The F13 and F15 scientific instruments, among others, include the special sensor ions, electrons, and scintillation (SSIES) thermal plasma analysis package.

We are particularly interested in the measurements taken by the ion drift meter (IDM), which provides measurements of the cross-track horizontal ion flow and the vertical ion flow $V_{\mathrm{Z}}$ (Rich and Hairston, 1994). The F13 and F15 vertical ion flow data are available at the DMSP SSIES data distribution webpage (http://cindispace.utdallas.edu/DMSP/) at the Center for Space Sciences at the University of Texas at Dallas and are provided at a $4 \mathrm{~s}$ resolution. This corresponds to a spatial resolution of $\sim 30 \mathrm{~km}$ considering the spacecraft velocity of $7.45 \mathrm{~km} \mathrm{~s}^{-1}$. All the DMSP data used here have the IDM best quality number, equal to 1 (for more details see http://cindispace.utdallas.edu/DMSP/intro.htm).

\section{Statistical results}

\subsection{Data selection and processing approach}

In order to characterise the high-latitude neutral density anomalies measured by CHAMP, we used the relative density variations since this quantity is less dependent on sampling height (CHAMP orbit decayed from 460 to $320 \mathrm{~km}$ ) and from the seasonal scale height variations. We adopted the definition for the relative density enhancement, as specified by Rentz and Lühr (2008)

$\rho_{\text {rel }}=\frac{\rho}{\rho_{\text {back }}}$,

where $\rho$ is the density derived from the CHAMP readings according to Eq. (2), and $\rho_{\text {back }}$ is the background density $\rho_{\text {back }}=\rho_{\text {MSIS }}+\rho_{\text {bias }}$. Here $\rho_{\text {bias }}$ is a linear bias function derived from the difference between observation and model density, and $\rho_{\text {MSIS }}$ is the NRLMSISE-00 (Naval Research Laboratory Mass Spectrometer and Incoherent Scatter) model density (Picone et al., 2002). The technique of bias density determination has been applied to every CHAMP satellite orbit. We use an orbit arc stretching from 49 to $49^{\circ}$ of MLat across the geomagnetic pole. The differences in density between the model and observations are taken at the end points $49^{\circ}$ and $49^{\circ}$ MLat and at the highest MLat point of orbit. The two linear functions between these three values are regarded as the bias density $\rho_{\text {bias }}$ (Fig. 1).

FACs are an important mechanism for transferring energy to the high-latitude ionosphere. It was shown that density anomalies in the cusp region are accompanied by SSFACs during both quiet (Lühr et al., 2004; Ritter and Lühr, 2006) and active (Liu et al., 2010) geomagnetic periods. The SSFACs have a filamentary structure and vary rapidly between positive and negative values. Because of this fluctuating character we use the root mean square (RMS) values of the SSFACs to represent their intensity. We calculated RMS values from intervals of $18 \mathrm{~s}$ at distances of $10 \mathrm{~s}$.

The electron temperature data derived from CHAMP and the vertical plasma drift data derived from DMSP F13 and F15 satellites are used as provided. Nevertheless, the DMSP IDM data come with a quality IDM number from 1 to 4 , referring to good, caution, poor, and undetermined, 


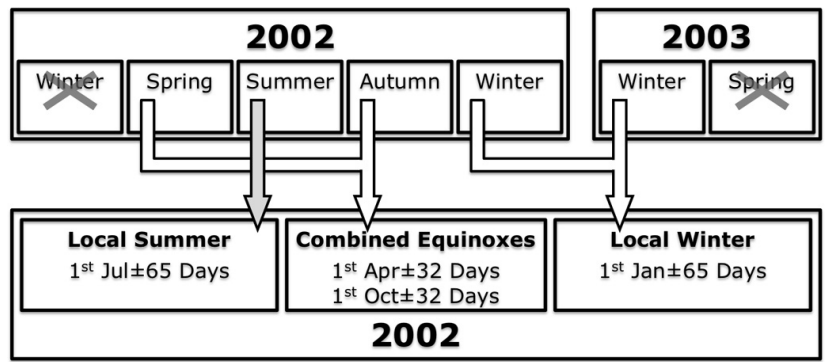

Fig. 2. The seasonal subdivision shown for the year 2002 in the Northern Hemisphere. Three seasons of about 130 days each are shown: local winter (1 January \pm 65 days); combined equinoxes ( 1 April \pm 32 days and 1 October \pm 32 days); local summer (1 July \pm 65 days).

respectively. The vertical velocity data used here have all IDM quality 1.

To examine seasonal variations we subdivided the available data into three seasons of about 130 days each, local winter ( 1 January \pm 65 days), combined equinoxes (1 April \pm 32 days and 1 October \pm 32 days), and local summer (1 July \pm 65 days). The interval of 130 days corresponds to the time needed by CHAMP to visit all local times. Figure 2 shows as an example the seasonal subdivision for the year 2002 in the Northern Hemisphere. As can be seen, the local winter for 2002 is centred at 1 January 2003. This is done to avoid a combination of largely separated parts from January and December 2002 with quite different geomagnetic and solar conditions.

To investigate the statistical properties and to obtain the internal relationship between density anomaly $\rho_{\text {rel }}$, electron temperature $T_{\mathrm{e}}$, SSFACs, and vertical velocity $V_{\mathrm{z}}$, statistical surveys based on a binning procedure (Sect. 3.2) and a superposed epoch analysis (SEA) methods (Sect. 3.3) are applied. However, only the Northern Hemisphere is taken into consideration because DMSP satellites cover the cusp region in the Southern Hemisphere very poorly.

\subsection{The spatial distribution of the anomalies}

In this section, we present an investigation of the statistical properties of the density enhancements $\rho_{\text {rel }}$, electron temperature $T_{\mathrm{e}}$, SSFACs, and vertical velocity $V_{\mathrm{z}}$, which covers 4 yr of CHAMP (March 2002-March 2006) and DMSP (March 2002-December 2005) measurements. The survey results are presented in MLat versus MLT dial plots reaching from 49 to $89^{\circ}$ MLat. They are based on a binning procedure similar to the one applied by Lühr et al. (2007). We take into consideration measurements made by satellites above $49^{\circ}$ MLat, since we are interested in high-latitude features. The MLat-MLT coordinate frame is used here to present the bin-averaged results, which cover the $24 \mathrm{~h}$ of MLT and $40^{\circ}$ of MLat. The given area is divided into 20 concentric rings centered on the geomagnetic pole. Each of these rings has a width of $2^{\circ}$ in MLat. Each ring is subdivided into equal-area bins starting from the innermost ring with 6 sectors and finishing with the outermost ring with 120 sectors. Therefore, each $N$-th ring is subdivided into $N \times 6$ sectors and each bin has an area of about $220 \times 232 \mathrm{~km}$. The readings of $\rho_{\text {rel }}, T_{\mathrm{e}}$, SSFACs, and $V_{\mathrm{z}}$ are binned according to the satellite position in MLat and MLT coordinates, after having subdivided the data into the three local seasons. Finally, the bin-averaged median values are used to present the statistical properties of the given data in the MLat-MLT frame (Figs. 3 and 4).

Figure 3 shows the resulting distribution of the relative density anomaly $\rho_{\text {rel }}$, SSFAC, and electron temperature $T_{\mathrm{e}}$ from top to bottom, respectively, for the three local seasons: winter, combined equinoxes, and summer from left to right. The density anomaly peaks (top row) appear in every season and their amplitudes show practically no seasonal dependence. However, their locations tend to expand from winter to summer more towards the equator and in local time they have a width of about $\pm 2 \mathrm{~h}$ centered at 12:00 MLT. This confined dayside cusp signature of the density anomalies is clearly visible in all three seasons. During winter the density anomaly peaks are located between $70^{\circ}$ and $80^{\circ}$ MLat, which expand to about $64-80^{\circ}$ MLat towards the summer. In addition to these major peaks there are secondary maxima with values well above the ambient level, which are observed in the midnight/premidnight region at about $70^{\circ}$ MLat. The intensity of these peaks shows some seasonal dependence: strong to week from winter to summer. These enhancements have been related to the substorm process by Liu et al. (2005) and studied by Ritter et al. (2010). Interestingly, there are also mass density depletions observed. They are most prominent in the dawn sector and visible in all seasons. Conversely, on the dusk side we find a seasonal dependence. Here we observe a density enhancement during winter and depletion in summer. These density structures are probably caused by the combined action of Joule heating and thermospheric circulation. However, a detailed discussion of this topic is beyond the scope of this paper.

Enhanced SSFAC activity can be observed in the dayside cusp region covering about $4-6^{\circ}$ in latitude, between $74^{\circ}$ and $80^{\circ}$ MLat, and stretching along local time, between 06:00 and 14:00 MLT (Fig. 3, middle row). The current density shows strong seasonal intensity variation from weak in winter to strong in summer. Electron temperature is shown in the bottom row of Fig. 3. Also, here strong seasonal variations are evident in the dayside cusp region. They are superposed on the strong background temperature increasing from winter to summer.

Figure 4 shows bin-averaged median values of ion vertical velocity $V_{\mathrm{z}}$ for the DMSP F15 (Fig. $4 \mathrm{a}$ ) and the DMSP F13 (Fig. 4b middle row) satellites. Local seasons are presented in the same way as in Fig. 3. As expected, DMSP satellites do not cover the full MLat-MLT frame, because of their Sunsynchronous, fixed local time orbits. Fortunately, both F13 and F15 satellites provide good coverage of the cusp region. 


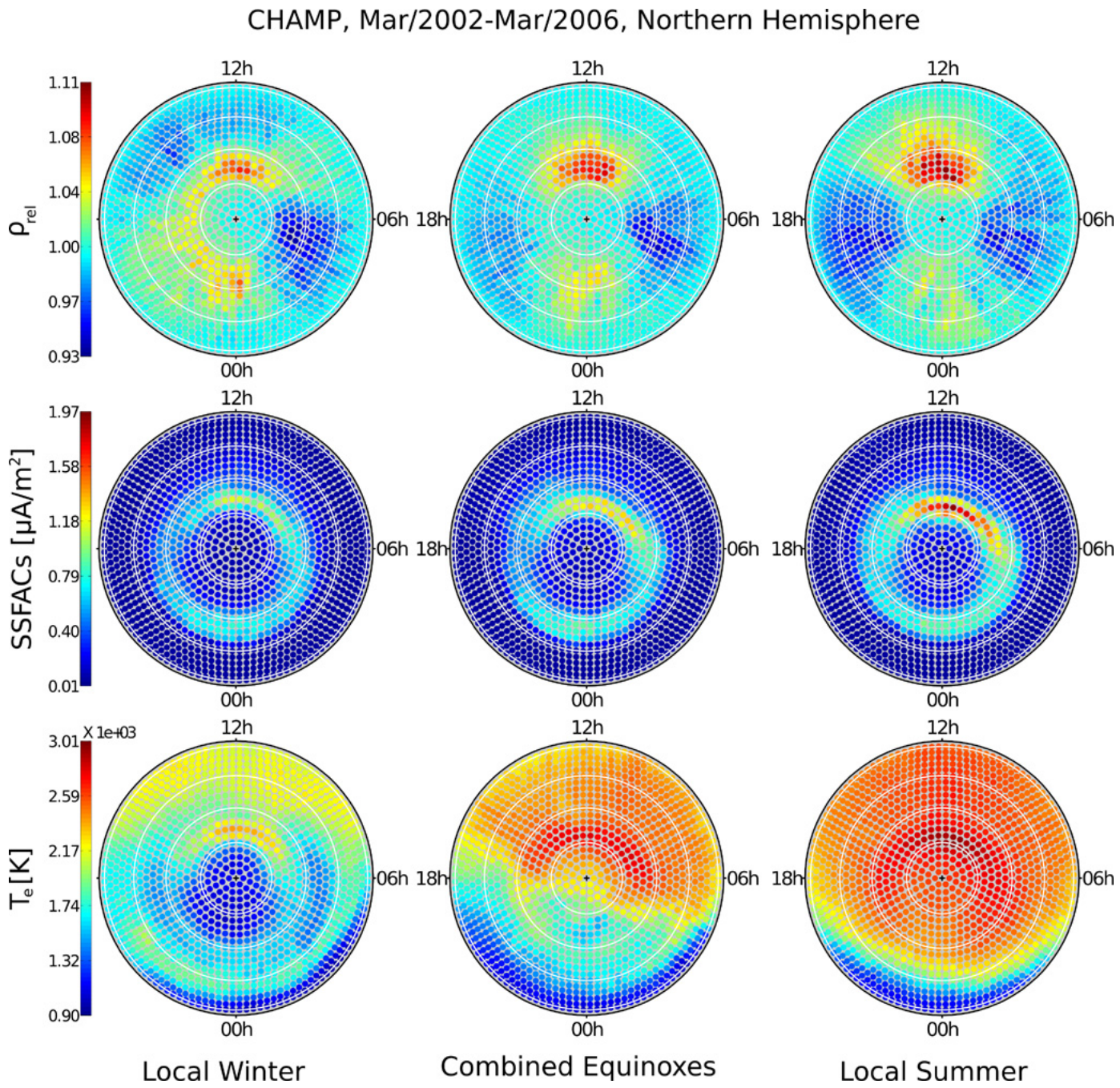

Fig. 3. The bin-averaged median values of density anomaly $\rho_{\text {rel }}$, SSFACs, and electron temperature $T_{\mathrm{e}}$ from top to bottom, respectively, for the three local seasons: winter (left column), combined equinoxes (middle column), and summer (right column). The white circles mark the MLat at $10^{\circ}$ spacing.

The quality of the cusp region coverage can be improved by combining F13 and F15 observations (Fig. 4b bottom row).

Although both satellites show on average positive, upward flow in the cusp region, this is about twice as high in the case of F15 (Fig. 4a) and there is a different seasonal dependence of vertical ion velocity in the cusp region: F13 shows a stronger seasonal variation than F15. In the cusp region the F13 observations indicate the positive ion up-flow intensities that decrease from strong to week from winter to summer (Fig. 4b, middle row). A positive up-flow is observed also in other regions during winter and the equinox, while in local summer the positive upward flow is present only in the cusp region. In the polar cap the ion drift is downward at all seasons, as expected (Coley et al., 2006). A somewhat different picture emerges in Fig. 4a from F15 observations. During equinox and summer the expected downward drift is not observed in the polar cap region. Also, high intensity stripes can be seen at dayside latitudes for all three seasons. According to Hartman and Heelis (2007) the upward flow in the polar cap region could arise from uncertainties of F15 altitude pointing. The authors have estimated this uncertainty in the equatorial region and found out that it results in velocity biases of $70 \mathrm{~m} \mathrm{~s}^{-1}$ to $140 \mathrm{~m} \mathrm{~s}^{-1}$, which could explain the observed differences in velocity. To solve this problem for our study we have applied another procedure, which is based on a comparison with F13 data (Wang et al., 2012). Namely we have used the F13 data as a reference and have rescaled the F15 data applying a linear relationship, which is derived from a correlation of overlapping F13 and F15 satellite readings. Median values are taken only from bins to which both satellites have contributed. Outliers were rejected based on their standard deviation values. After the third iteration the following linear scaling expression has been derived for the ion vertical velocity in $\mathrm{m} \mathrm{s}^{-1}$ 
a) DMSP F15, Mar/2002-Dec/2005, Northern Hemisphere

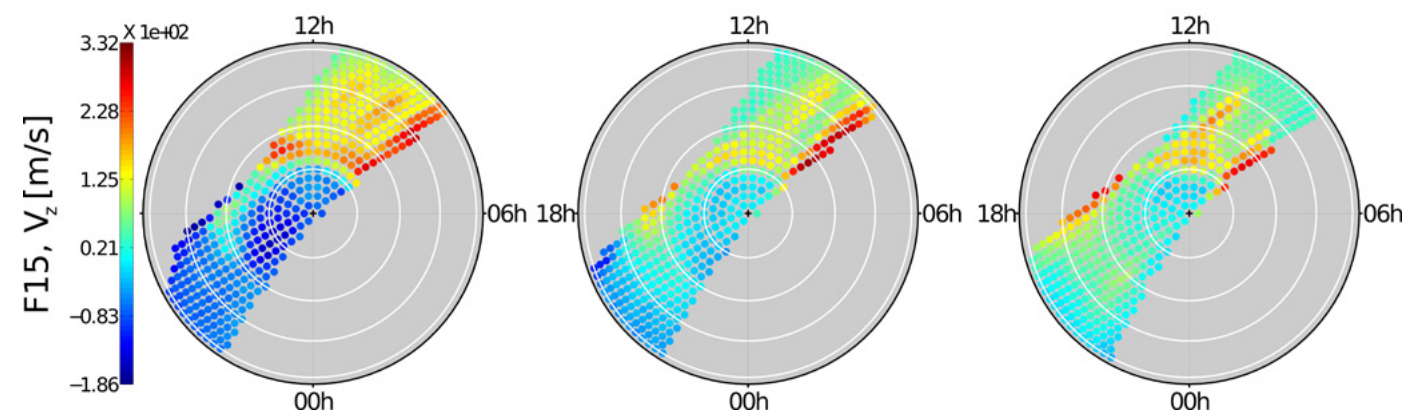

b) DMSP F13 and F15 (rescaled), Mar/2002-Dec/2005, Northern Hemisphere
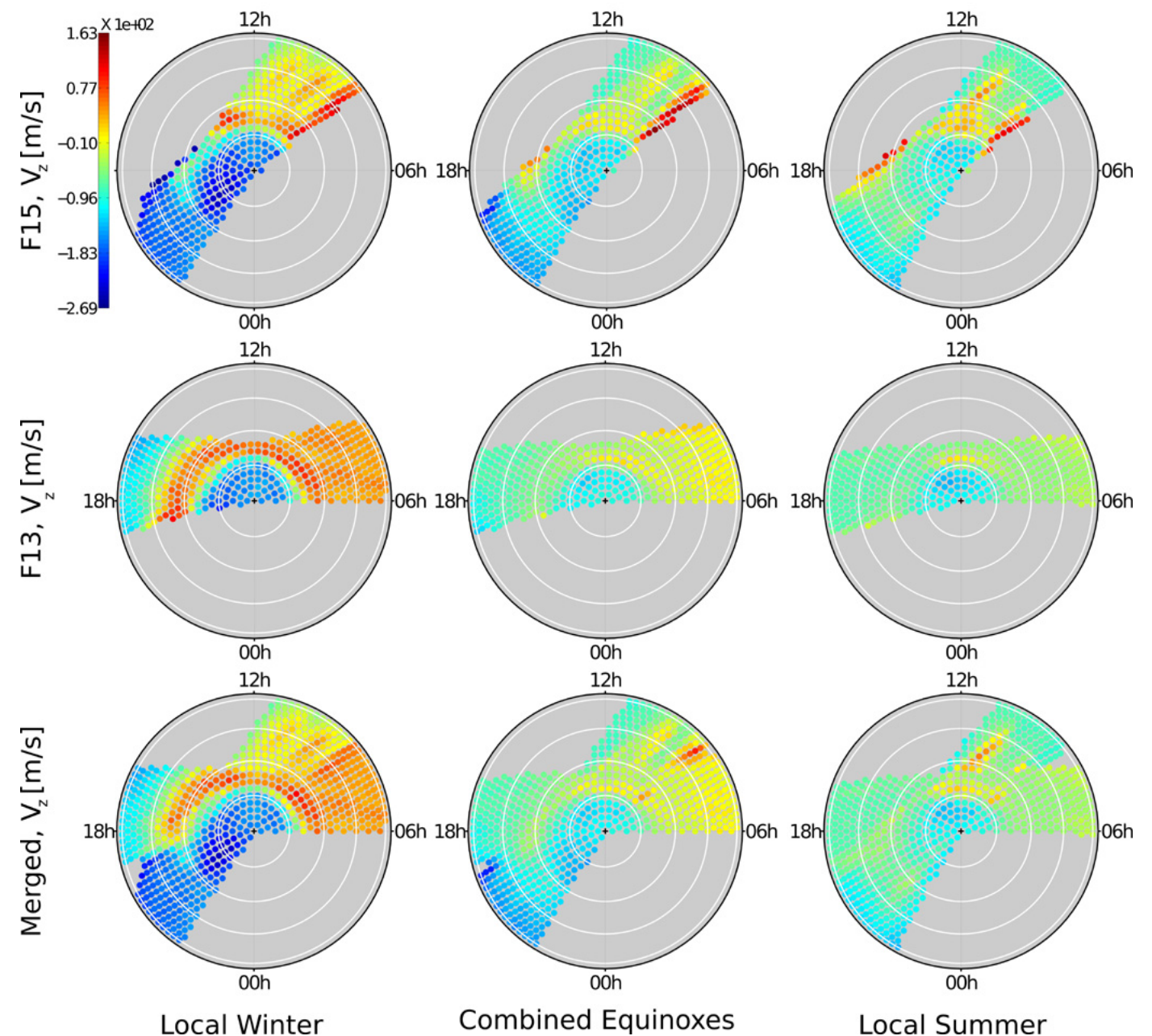

Fig. 4. The bin-averaged median values of ion vertical velocity for the three local seasons: winter (left column), combined equinoxes (middle column), and summer (right column): (a) DMSP F15; (b) rescaled DMSP F15 (according to Eq. 6), DMSP F13, and their merged plots from top to bottom. The white circles mark the MLat at $10^{\circ}$ spacing.

$V_{\mathrm{z}}^{\mathrm{F} 15^{\text {new }}}=0.84 V_{\mathrm{z}}^{\mathrm{F} 15^{\text {old }}}-113.7$

with a correlation coefficient 0.93 . These rescaled values of F15 (Fig. 4b, top row) ion vertical velocity are used for the
SEA analysis in Sect. 3.3. As we can see from Fig. 4b (top row) the rescaled F15 data shows downward ion drift in the polar cap, as expected, during all seasons. The merged plots of F13 and F15 satellites data are shown in Fig. 4b (bottom row). 


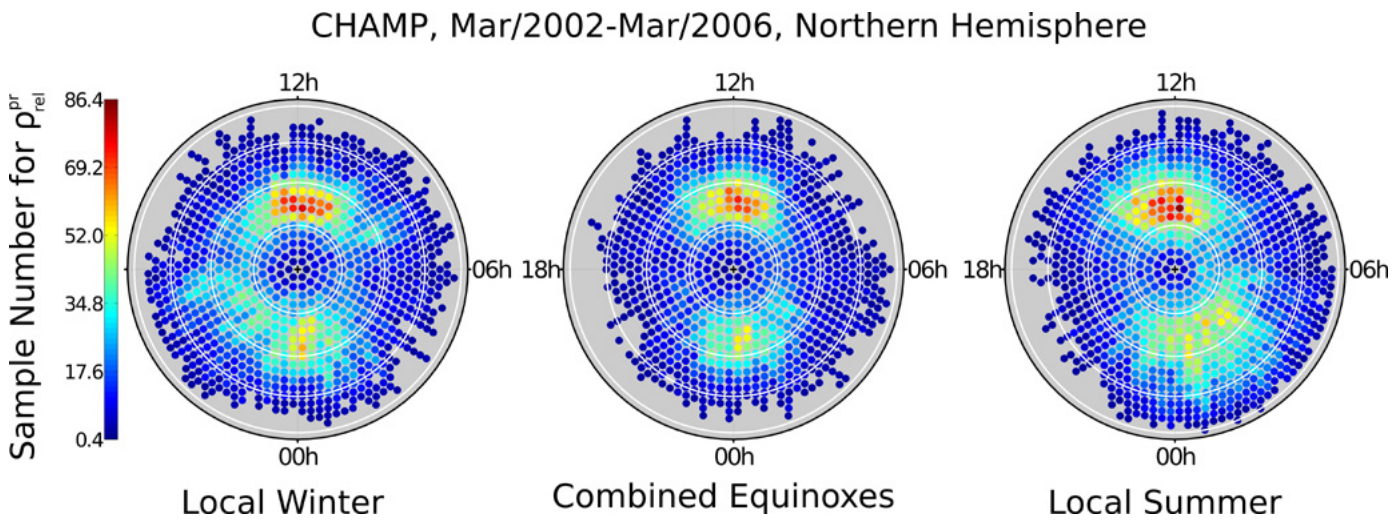

Fig. 5. Sample number distribution per bin for $\rho_{\text {rel }}^{\mathrm{pr}}$ normalized by the number of passes over that bin is shown for the three local seasons: winter (left column), combined equinoxes (middle column), and summer (right column). The white circles mark the MLat at $10^{\circ}$ spacing.

We can easily identify the cusp signature at all seasons and in all quantities shown in Figs. 3 and $4 \mathrm{~b}$. The density anomaly has a clearly visible confined dayside cusp signature (Fig. 3, top row). Also SSFACs, electron temperature, and ion vertical velocity show a confined stretched shape of maximum value distributions in the cusp region.

\subsection{The spatial correlation of the various parameters}

To investigate the relationship between the various presented quantities in more detail we have performed a superposed epoch analysis (SEA) between thermospheric density anomaly, SSFACs, electron temperature, and ion vertical drift. The time and location of the peak in thermospheric mass density from CHAMP data are used as reference parameters for the SEA method.

We take into account only prominent (pr) density enhancements, $\rho_{\text {rel }}$ with values larger than 1.2

$\rho_{\text {rel }}^{\mathrm{pr}} \equiv \rho_{\text {rel }}>\rho_{\text {rel }}^{\mathrm{thr}}=1.2$.

Such a density anomaly threshold (thr) has earlier been used by Liu et al. (2010). Figure 5 shows the sample distribution of $\rho_{\mathrm{rel}}^{\mathrm{pr}}$ separately for the seasons. Here the sample number of $\rho_{\mathrm{rel}}^{\mathrm{pr}}$ per bin is normalized by the number of passes over that bin. As we can see, the density anomaly shows a clearly confined cusp signature at all seasons.

Time and location of the prominent density enhancement $\rho_{\text {rel }}^{\mathrm{pr}}$ define the "reference time" and "reference latitude" if the anomaly falls into the window confined to 08:00-16:00 MLT and $60-80^{\circ}$ MLat. We have treated these events separately for northbound and southbound passes, but afterwards these results were joined. Around every density anomaly we consider a data interval of $\pm 4 \mathrm{~min}$ ( $\pm 1800 \mathrm{~km}$ arc length). Concurrent CHAMP measurements of SSFAC and electron temperature for all the events are stacked, centered at the reference latitude, and then the average curves are resampled at $1^{\circ}$ in MLat. For the consideration of ion drift from DMSP, only observations from close approaches have been used. A close approach demands that: (a) DMSP passes the reference latitude at a universal time within $\pm 0.5 \mathrm{~h}$ of the reference time; (b) ion velocity, $V_{\mathrm{z}}$, data must fall in a $\pm 5^{\circ}$ MLat by $\pm 1 \mathrm{~h}$ MLT window centered at the reference location of the anomaly. Ion vertical velocities, $V_{\mathrm{z}}$ used here for the SEA analysis include readings from both the F13 and F15 satellites. The used $V_{\mathrm{z}}^{\mathrm{F} 15}$ values have been rescaled according to Eq. (6).

Figure 6 shows the average latitude profiles of $\rho_{\text {rel }}$, SSFACs, $T_{\mathrm{e}}$, and $V_{\mathrm{z}}$ values with respect to the reference latitude separately for local winter, combined equinoxes, and local summer (from left to right). The error bars represent the standard deviations of $1^{\circ}$ MLat bins. The reference MLat point, defined by the $\rho_{\mathrm{rel}}^{\mathrm{pr}}$ maximum, is presented as $\Delta$ MLat equal to zero. Positive values on this scale represent poleward latitude. The mean density enhancement shows peak values of 1.33 and no seasonal variations (Fig. 6, top row). As expected, clear $\rho_{\text {rel }}^{\mathrm{pr}}$ peaks can be identified at all three seasons.

Mean seasonal variations of SSFACs related to the density anomaly are shown in Fig. 6 (second row). There are pronounced peaks between $-1^{\circ}$ and $0^{\circ} \Delta$ MLat at all seasons. The seasonal dependence of SSFAC intensity is observable with increasing amplitudes towards local summer. The RMS values are equal to $2.00,2.38$, and $2.56 \mu \mathrm{A} \mathrm{m}^{-2}$ for winter, combined equinoxes, and summer, respectively. Therefore, the intensity has increased by $19 \%$ and $36 \%$ in equinox and summer, respectively.

Figure 6 (third row) presents the derived latitude profiles of electron temperature. As expected, the seasonal dependence of the temperature is evident, but also a $T_{\mathrm{e}}$ peak at the reference latitude can be identified. The total temperature increases towards summer including the peak value at $0^{\circ} \Delta$ MLat, while the shape of this peak changes from relatively high and narrow in winter to low and broad in summer.

Figure 6 (last row) presents the SEA profiles of the ion vertical velocity at DMSP altitude. The strong seasonal variation of the velocity peak at the reference $\left(0^{\circ} \Delta\right.$ MLat $)$ can be seen. The maximum velocity decreases by more than $50 \%$ 

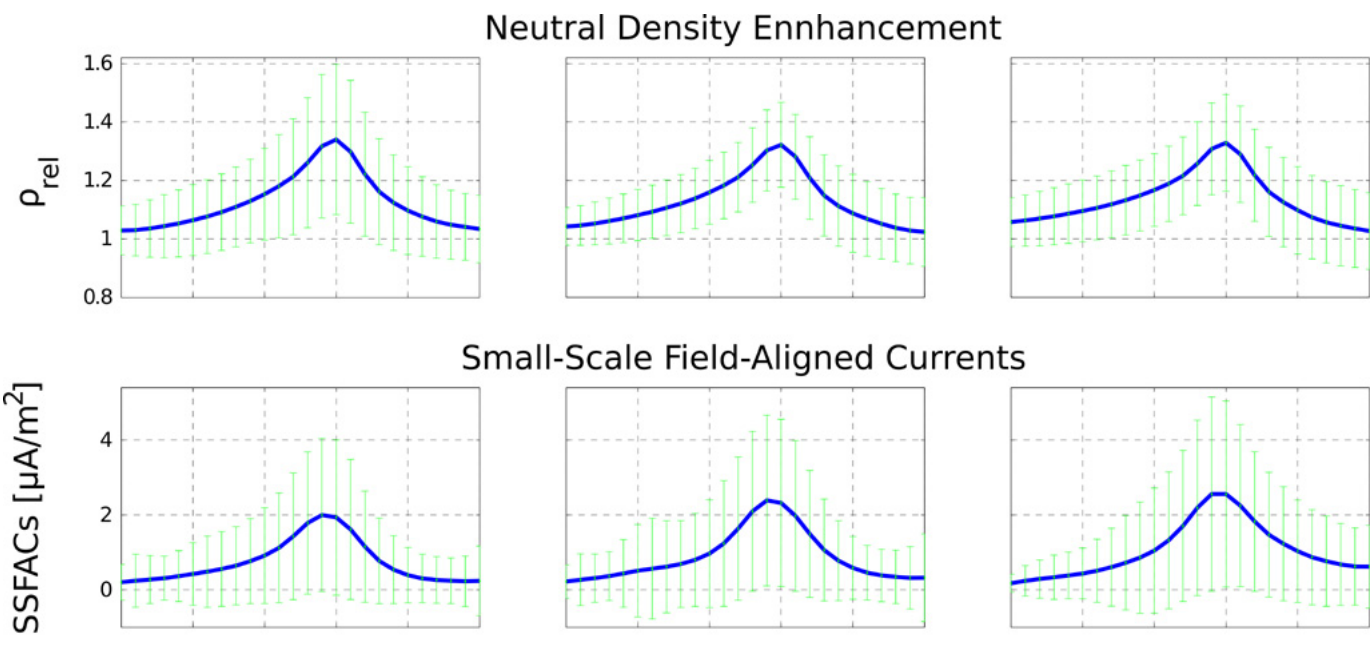

Small-Scale Field-Aligned Currents
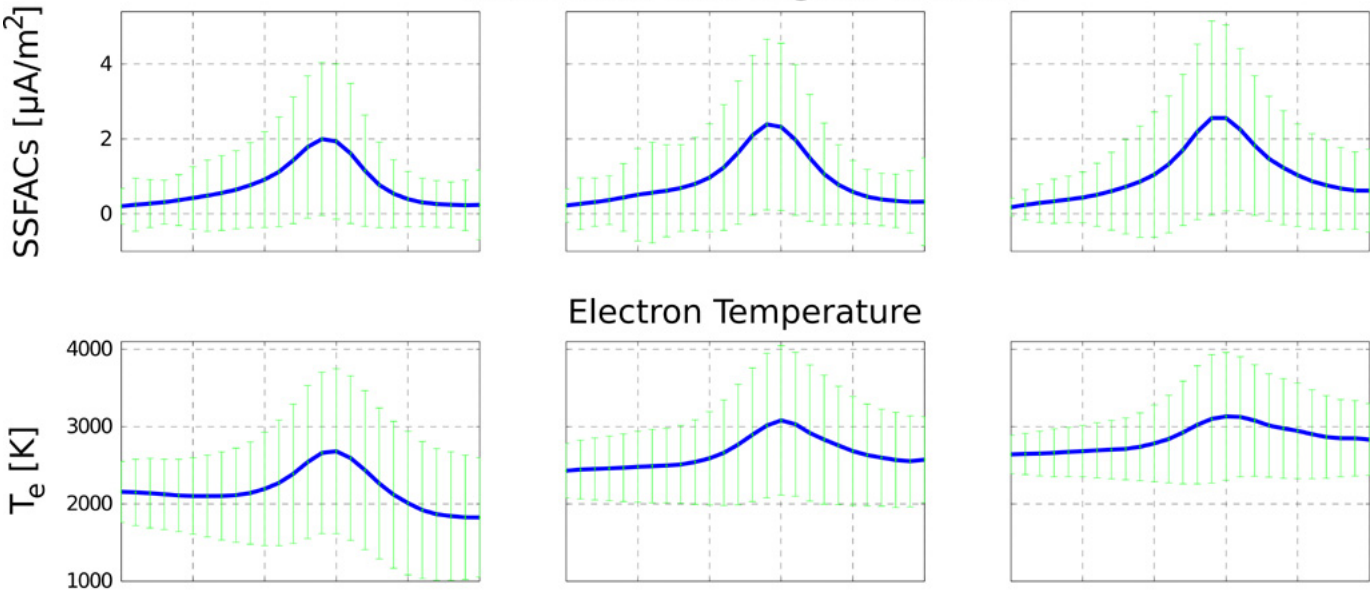

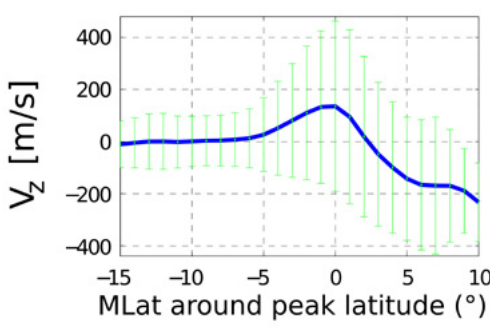

Local Winter

\section{Ion Vertical Velocity}

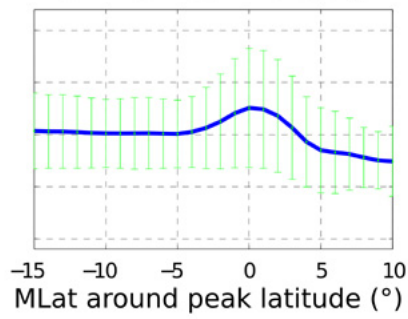

Combined Equinoxes

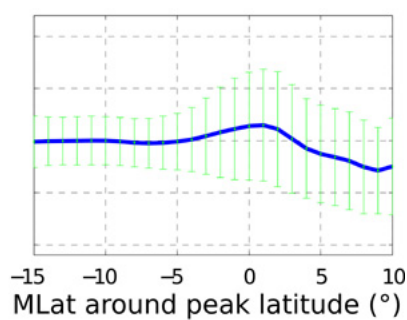

Local Summer

Fig. 6. The superposed epoch analysis results for latitude profiles of $\rho_{\text {rel }}$, SSFACs, $T_{\mathrm{e}}$, and $V_{\mathrm{z}}$ values from top to bottom, respectively, for the three local seasons: local winter (left column); combined equinoxes (middle column); local summer (right column). The error bars represent the standard deviations of $1^{\circ}$ MLat averages. Used data covers 4 yr (March 2002-March 2006) of CHAMP and 4 yr (March 2002December 2005) of DMSP observations in the Northern Hemisphere.

from winter to summer. It is equal to 136,102 , and $57 \mathrm{~m} \mathrm{~s}^{-1}$ in winter, combined equinoxes, and summer, respectively.

An important observation, clearly visible at all three seasons in Fig. 6, is that all considered variables show a clear peak centered at the $0^{\circ} \Delta$ MLat, which was defined according to $\rho_{\mathrm{rel}}^{\mathrm{pr}}$ at CHAMP altitude. Also, for all discussed variables the presented SEA results show the same seasonal dependence, as they were evident in Figs. 3 and 4. The possible relationship derived from the SEA between the quantities $\rho_{\text {rel }}$, SSFACs, $T_{\mathrm{e}}$, and $V_{\mathrm{z}}$ will be discussed in the subsequent sections.
Table 1. The full latitudinal width at half maximum (FWHM) of $\rho_{\text {rel }}$, SSFAC, $T_{\mathrm{e}}$, and $V_{\mathrm{z}}$ in the Northern Hemisphere covering $4 \mathrm{yr}$ (March 2002-March 2006) of CHAMP and 4 yr (March 2002December 2005) of DMSP observations for different local seasons.

\begin{tabular}{lcccc}
\hline Seasons & $\rho_{\text {rel }}\left[{ }^{\circ}\right]$ & SSFAC $\left[{ }^{\circ}\right]$ & $T_{\mathrm{e}}\left[{ }^{\circ}\right]$ & $V_{\mathrm{z}}\left[{ }^{\circ}\right]$ \\
\hline Local winter & 6 & 5 & 5 & 5 \\
Combined equinoxes & 6 & 6 & 6 & 4 \\
Local summer & 6 & 6 & 7 & 5 \\
\hline
\end{tabular}




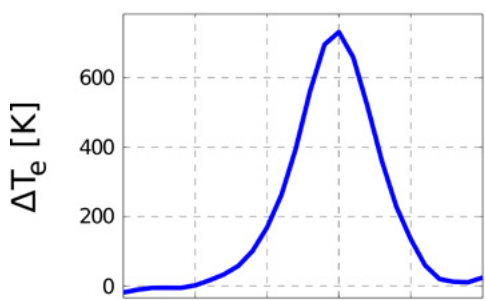

\section{Electron Temperature}

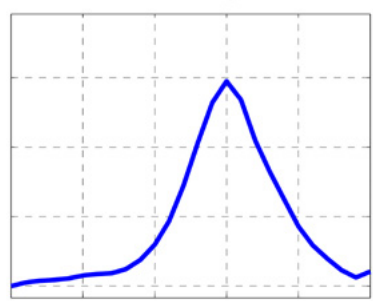

Ion Vertical Velocity

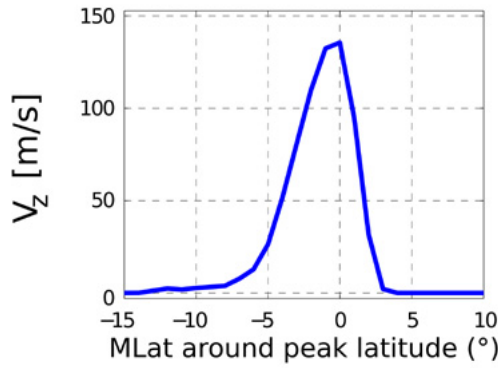

Local Winter

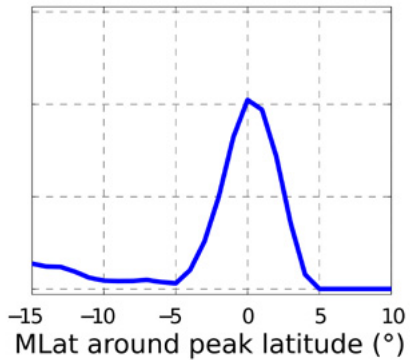

Combined Equinoxes
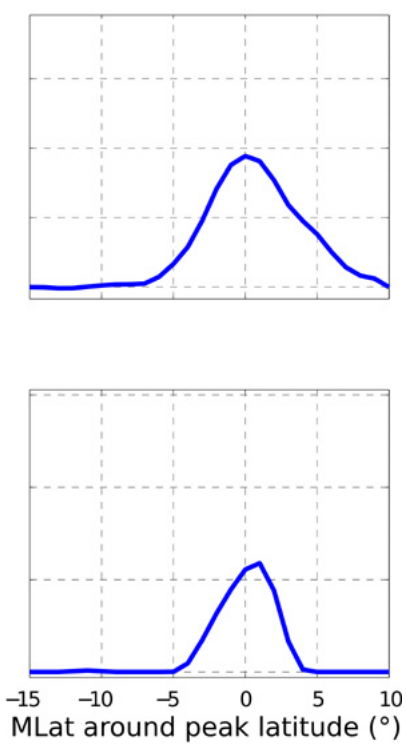

Local Summer

Fig. 7. Electron temperature rise $\Delta T_{\mathrm{e}}$ (top row) and ion vertical velocity $V_{\mathrm{Z}}$ (bottom row) with the background removed for the three local seasons. Data are the same as in Fig. 6.

\subsection{Similarity between electron temperature and verti- cal ion drift variations}

Before we focus on the electron temperature seasonal variations, emerging from the SEA analysis, we calculate the full width at half maximum (FWHM) of the peaks at $0^{\circ} \Delta$ MLat shown in Fig. 6. The FWHM is a statistical characteristic of the horizontal scale size. The results are listed in Table 1 for the values of $\rho_{\text {rel }}$, SSFAC, $T_{\mathrm{e}}$, and $V_{\mathrm{z}}$. In order to calculate FWHM, the background values have to be removed from the curves presented in Fig. 6. This is done by using a linear interpolation taken between the two minimum values at different sides of the reference latitude $\left(0^{\circ} \Delta\right.$ MLat). An exception is the case of vertical velocity, where all the negative values from the polar cap region are replaced with zeros. Derived values are then normalized by their maxima. This means the peak has a value equal to one, and therefore the MLat width at 0.5 is equal to FHWM. As we can see from Table 1, the FWHM values show practically no seasonal variation and are about $6^{\circ}$ for $\rho_{\text {rel }}$ and SSFAC, and about $5^{\circ}$ for $V_{z}$. The electron temperature FWHM value shows a slight increase towards summer from 5 to $7^{\circ}$. This together with Fig. 6 (third row) suggests that the peak value of the electron temperature rise decreases and smears out from winter to summer. Electron temperature features in the cusp region have earlier been studied by Prölss (2006). He also found a confined $T_{\mathrm{e}}$ enhancement in the cusp region with a mean value of the FWHM of about $4^{\circ}$ in latitude. This is somewhat less than the width reported here. From the difference between the results we conclude that the mass density and $T_{\mathrm{e}}$ peaks are not exactly at the same locations, and thus the temperature peak is somewhat smeared out by the SEA. This seems to be most prominent during summer season.

A comparison of the electron temperature with the ion vertical velocity is the next logical step. Figure 7 shows curves of the electron temperature rise $\Delta T_{\mathrm{e}}$ and ion vertical velocity $V_{\mathrm{z}}$ where the background values are removed (see discussion above) for the different seasons. We can clearly identify the same seasonal variations for both of them. Their peak intensities decrease towards summer by $20 \%$ and $48 \%$ for $\Delta T_{\mathrm{e}}$ and by $25 \%$ and $58 \%$ for $V_{\mathrm{z}}$ in combined equinoxes and local summer, respectively. The similarity we find suggests that there may be a certain linear correlation between electron temperature and ion vertical velocity variations.

Table 2 lists the linear regression functions $V_{\mathrm{z}}=a \Delta T_{\mathrm{e}}+b$ and correlation coefficients separately for the local seasons and for a combined analysis (last row). Here, $a$ is a slope and $b$ is an offset of the regression line. The linear regression and correlation coefficients are calculated using data around the peak location from -5 to $5^{\circ} \Delta$ MLat in Fig. 7 . For different seasons the slope varies between $0.22 \mathrm{~m}(\mathrm{sK})^{-1}$ and $0.24 \mathrm{~m}(\mathrm{sK})^{-1}$, and offsets vary between $-21 \mathrm{~m} \mathrm{~s}^{-1}$ and $-38 \mathrm{~m} \mathrm{~s}^{-1}$. The correlation coefficient varies between 0.93 and 0.96 among seasons and is highest at local winter, when omitting two outliers (Fig. 8). If we make a correlation analysis using the data from all seasons together (without two outliers), the convincing linear regression $V_{\mathrm{z}}=0.23 \Delta T_{\mathrm{e}}-31$ with a correlation coefficient 0.96 emerges. Figure 8 shows 
Table 2. Correlation analysis between the ion vertical velocity $V_{\mathrm{Z}}$ and electron temperature rise $\Delta T_{\mathrm{e}}$ in the Northern Hemisphere. The linear regression functions $V_{\mathrm{z}}=a \Delta T_{\mathrm{e}}+b$ and correlation coefficients for the seasons separately and for all seasons together, where $a$ is a slope and $b$ is an offset.

\begin{tabular}{lcc}
\hline Seasons & $\begin{array}{c}V_{\mathrm{Z}}=a \Delta T_{\mathrm{e}}+b \\
\left.\left[\mathrm{~m} \mathrm{~s}^{-1}\right]=\left[\mathrm{m} \mathrm{K}^{-1}\right)^{-1}\right][\mathrm{K}]+\left[\mathrm{m} \mathrm{s}^{-1}\right]\end{array}$ & Correlation coefficients \\
\hline Local winter & $a=0.22 ; b=-21$ & 0.96 \\
Combined equinoxes & $a=0.24 ; b=-38$ & 0.95 \\
Local summer & $a=0.22 ; b=-27$ & 0.93 \\
All seasons together & $a=0.23 ; b=-31$ & 0.96 \\
\hline
\end{tabular}

correlation analysis results for all local seasons together with and without the two outliers, which come from local winter.

\section{Discussion}

The main purpose of this paper is to present the relationship of the thermospheric density anomaly with small-scale FAC, electron temperature, and ion vertical velocity using $4 \mathrm{yr}$ of observations from CHAMP and DMSP in the Northern Hemisphere. The statistical study allows us to have a closer look at the seasonal variations of the coordinated CHAMP and DMSP data at two different altitudes $(400 \mathrm{~km}$ and $840 \mathrm{~km}$ ). An important finding of the SEA analysis is that the ionospheric quantities SSFAC, $T_{\mathrm{e}}$ and $V_{\mathrm{z}}$ exhibit local maxima in close temporal and spatial vicinity to the mass density peak in the cusp region. However, there are differences in intensity variations of the seasonal behaviour between the SSFAC, $T_{\mathrm{e}}$, and $V_{\mathrm{z}}$ curves, while $\rho_{\text {rel }}$ shows no significant seasonal variation (Fig. 6). Namely, the peak intensity of the SSFAC tends to increase towards summer, while $V_{\mathrm{z}}$ decreases. In general, the total electron temperature values also increase from winter to summer, but the behaviour of the temperature enhancement at $0^{\circ} \Delta$ MLat is somewhat different (Fig. 6, third row).

Another important finding is the close similarity between electron temperature and vertical ion drift variations in the cusp region. A high degree of correlation (Fig. 8) suggests that there could be a causal relationship between $V_{\mathrm{z}}$ and $\Delta T_{\mathrm{e}}$, which varies only little from season to season (Table 2). The possible relationship between these two variables was earlier discussed, e.g. by Moen et al. (2004) and Strangeway et al. (2005) based on observations made on 20 December 1998 and between 24 and 25 September 1998 during geomagnetic storms, respectively. Electron precipitation was suggested as the controlling parameter for ion upwelling, based on electron heating and an associated ambipolar electric field. Prölss (2008) investigated the correlation between density changes, temperature changes, and ion velocity perturbations using DE-2 satellite observations. In most of the considered cases the electron density decrease was observed at the location of the temperature enhancement (Prölss, 2006, 2008). Additionally an increase in the vertical ion velocity was observed dur-

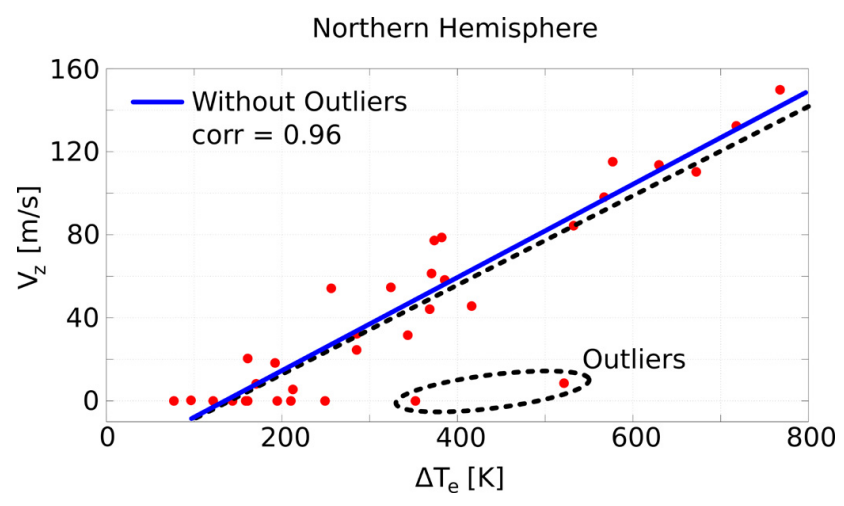

Fig. 8. Correlation analysis results between ion vertical velocity $V_{\mathrm{Z}}$ and electron temperature rise $\Delta T_{\mathrm{e}}$ in the Northern Hemisphere. The regression line and correlation coefficient ("corr") apply to the total data set independent of season.

ing disturbed conditions (Prölss, 2008). The author suggested the electron density drop as the main cause for the electron temperature enhancement. We plan to investigate this interesting effect in a later study using CHAMP electron density and electron temperature data. Sadler et al. (2012) concluded, based on a single event observed by the CHAMP and FAST (Fast Auroral Snapshot) satellites and by an enhanced data simulation, that soft electron precipitation causes $T_{\mathrm{e}}$ enhancement, and in cooperation with ion up-flow it is a possible driver also for mass density upwelling (Lühr et al., 2004) in the cusp region.

Rentz and Lühr (2008) and Lühr and Marker (2013) suggested Joule heating as the primary driving mechanism for the density anomalies observed by CHAMP at high latitudes during moderately active and quiet geomagnetic times (2002-2005). SSFACs and particle precipitation were identified as energy deposition mechanisms. Liu et al. (2010) studied density anomalies in the polar cap during geomagnetic storms (2002-2005) and showed that half of the events are not directly accompanied by SSFACs. The authors suggested an ion up-flow mechanism as an alternative driver for neutral upwelling.

Our investigation is not limited to certain geomagnetic conditions, the density anomaly $\rho_{\text {rel }}$ at high altitudes was 
observed by the CHAMP satellite during both quiet and active geomagnetic conditions. Therefore, in our SEA analysis we take into account only prominent mass density enhancements, $\rho_{\text {rel }}^{\text {pr }}$ (Eq. 7), for event selection.

Our preferred suggestion is that intense soft particle precipitation has several effects influencing the ion and neutral dynamics in different ways. But still, the two phenomena, neutral upwelling and ion up-flow occur at the same time and same location, as our study has shown. On the one hand soft electron precipitation creates a conducting layer well above the E-layer $(100-130 \mathrm{~km})$. Intense Joule heating fuelled by SSFACs causes a significant temperature increase at altitudes below $200 \mathrm{~km}$, as shown by Lühr and Marker (2013). The hot air parcel then starts to lift up air and causes the mass density anomaly at CHAMP altitude. Another effect of the intense electron precipitation is heating of the electron gas in the auroral acceleration region. These hot electrons can expand rapidly along the magnetic field lines. As an effect the plasma scale height is significantly increased in these flux tubes due to intense heatflux, which accelerates the ions moving upward. Further down in the ionosphere the electron cooling mechanisms become effective (e.g. Schunk and Nagy, 2009), slowing down the vertical ion acceleration. The electron cooling mechanisms depend strongly on the ambient ion density. In the cusp region the plasma density is strongly enhanced during summer months compared to winter. This may well explain the larger $\Delta T_{\mathrm{e}}$ enhancement and vertical ion drift at wintertime.

When taking the relationship between $\Delta T_{\mathrm{e}}$ and $V_{\mathrm{Z}}$ shown in Fig. 8 literally, the vertical velocity is increased by $1 \mathrm{~m} \mathrm{~s}^{-1}$ for every $5 \mathrm{~K}$ electron temperature rise. Furthermore, the electron temperature enhancement has to surpass $150 \mathrm{~K}$ before the ions are lifted up. A detailed discussion of the mechanisms causing the ion up-flow will be part of a followup paper. Also any quantitative assessments of the relation between electron temperature rise and vertical plasma drift should await confirmation by the Swarm constellation mission, which will provide measurements of all the considered quantities (Friis-Christensen et al., 2008).

\section{Conclusions}

We have investigated the relationship between thermospheric density enhancements $\rho_{\text {rel }}$, SSFAC, electron temperature $T_{\mathrm{e}}$, and ion vertical velocity $V_{\mathrm{Z}}$ in the cusp region. Our statistical study covers both quiet and active geomagnetic times using 4 yr of data measured by CHAMP (March 2002March 2006) and DMSP (March 2002-December 2005) satellites in the Northern Hemisphere. The main conclusions drawn from superposed epoch analysis with reference to the $\rho_{\text {rel }}^{\mathrm{pr}}$ peak are:

1. All considered variables exhibit a clear peak concurrently with the mass density anomaly centered at the reference $0^{\circ} \Delta$ MLat for all three seasons (Fig. 6).
2. The mean amplitude of the prominent relative density enhancement peak shows no seasonal variations and amounts to $\rho_{\text {rel }}^{\mathrm{pr}} \sim 1.33$.

3. The dependence of the small-scale FAC intensity on ionospheric conductivity causes an increase of the SSFAC peak values towards local summer. The RMS value is equal to $2.00 \mu \mathrm{A} \mathrm{m}^{-2}$ in local winter and exhibits a $19 \%$ and $36 \%$ increase in combined equinoxes and local summer, respectively.

4. Values of electron temperature enhancement, $\Delta T_{\mathrm{e}}$, strongly decrease towards local summer. They are equal to $\sim 730 \mathrm{~K}$ in winter and decrease by about $20 \%$ and $48 \%$ during combined equinoxes and local summer, respectively.

5. The mean vertical plasma velocity $V_{\mathrm{z}}$ shows a pronounced seasonal variation with a strong decrease by more than $50 \%$ of its peak value over the seasons, and it is equal to 136,102 , and $57 \mathrm{~m} \mathrm{~s}^{-1}$ in local winter, combined equinoxes, and local summer, respectively.

6. There exist a clear linear relationship between $V_{\mathrm{z}}$ and $\Delta T_{\mathrm{e}}$, which varies only slightly from season to season (Table 2). Taking all seasons together, the following linear regression $V_{\mathrm{z}}\left[\mathrm{m} \mathrm{s}^{-1}\right]=0.23 \Delta T_{\mathrm{e}}-31$ emerges with a correlation coefficient 0.96 .

We suggest a common driver for the density anomaly and the ion up-flow in the cusp region. The root cause for both is magnetic reconnection at the dayside magnetopause. Resulting soft electron precipitation enhances the ionospheric conductivity, which allows for strong heating and upwelling of air parcels. At the same time precipitating electrons heat the electron gas, which causes an uplift of the plasma. Although the two effects occur concurrently in the cusp region, the mechanisms for moving the neutral and the charged particles may be quite different, as reflected in the different seasonal variation. Further studies are needed to fully understand and explain the mechanisms.

Acknowledgements. We gratefully acknowledge the Center for Space Sciences at the University of Texas at Dallas and the US Air Force for making available the DMSP thermal plasma data. The Deutsche Forschungsgemeinschaft (DFG) supported G. N. Kervalishvili through the Priority Programme "Planetary Magnetism" SPP 1488.

The service charges for this open access publication have been covered by a Research Centre of the Helmholtz Association.

Topical Editor K. Hosokawa thanks A. W. Yau and one anonymous referee for their help in evaluating this paper. 


\section{References}

Bruinsma, S., Forbes, J. M., Nerem, R. S., and Zhang, X.: Thermospheric density response to the 20-21 November 2003 solar and geomagnetic storm from CHAMP and GRACE accelerometer data, J. Geophys. Res., 111, A06303, doi:10.1029/2005JA011284, 2006.

Burchill, J. K., Knudsen, D. J., Clemmons, J. H., Oksavik, K., Pfaff, R. F., Steigies, C. T., Yau, A. W., and Yeoman, T. K.: Thermal ion upflow in the cusp ionosphere and its dependence on soft electron energy flux, J. Geophys. Res., 115, A05206, doi:10.1029/2009JA015006, 2010.

Clemmons, J. H., Hecht, J. H., Salem, D. R., and Strickland, D. J.: Thermospheric density in the Earth's magnetic cusp as observed by the Streak mission, Geophys. Res. Lett., 35, L24103, doi:10.1029/2008GL035972, 2008.

Clemmons, J., Friesen, L., Katz, N., Ben-Ami, M., Dotan, Y., and Bishop, R.: The Ionization Gauge Investigation for the Streak Mission, Space Sci. Rev., 145, 263-283, 2009.

Coley, W. R., Heelis, R. A., and Hairston, M. R.: Characteristics of high-latitude vertical plasma flow from the Defense Meteorological Satellite Program, J. Geophys. Res., 111, A11314, doi:10.1029/2005JA011553, 2006.

Demars, H. G. and Schunk, R. W.: Thermospheric response to ion heating in the dayside cusp, J. Atmos. Sol.-Terr. Phys., 69, 649660, 2007.

Doornbos, E., van den IJssel, J., Lühr, H., Förster, M., and Koppenwallner, G.: Neutral density and crosswind determination from arbitrarily oriented multiaxis accelerometers on satellites, J. Spacecr. Rock., 47, 580-589, 2010.

Friis-Christensen, E., Lühr, H., Knudsen, D., and Haagmans, R.: Swarm - An Earth Observation Mission investigating Geospace, Adv. Space Res., 41, 210-216, 2008.

Hartman, W. A. and Heelis, R. A.: Longitudinal variations in the equatorial vertical drift in the topside ionosphere, J. Geophys. Res., 112, A03305, doi:10.1029/2006JA011773, 2007.

Hoffman, R. A. and Schmerling, E. R.: Dynamics Explorer program: an overview, Space Sci. Instr., 5, 345-348, 1981.

Liu, H., Lühr, H., Henize, V., and Köhler, W.: Global distribution of the thermospheric total mass density derived from CHAMP, J. Geophys. Res., 110, A04301, doi:10.1029/2004JA010741, 2005.

Liu, R., Lühr, H., and Ma, S.-Y.: Storm-time related mass density anomalies in the polar cap as observed by CHAMP, Ann. Geophys., 28, 165-180, doi:10.5194/angeo-28-165-2010, 2010.

Liu, R., Ma, S.-Y., and Lühr, H.: Predicting storm-time thermospheric mass density variations at CHAMP and GRACE altitudes, Ann. Geophys., 29, 443-453, doi:10.5194/angeo-29-4432011, 2011.

Lühr, H. and Marker, S.: High-latitude thermospheric density and wind dependence on solar and magnetic activity, in: Climate And Weather of the Sun-Earth System (CAWSES): Highlights from a priority program, edited by: Lübken, F.-J., Springer, Dodrecht, the Netherlands, 189-206, 2013.

Lühr, H., Warnecke, J., and Rother, M. K. A.: An algorithm for estimating field-aligned currents from single spacecraft magnetic field measurements: A diagnostic tool applied to Freja satellite data, Geosci. Remote Sens., 34, 1369-1376, 1996.

Lühr, H., Rother, M., Köhler, W., Ritter, P., and Grunwaldt, L.: Thermospheric up-welling in the cusp region: Evidence from CHAMP observations, Geophys. Res. Lett., 31, L06805,
doi:10.1029/2003GL019314, 2004.

Lühr, H., Rentz, S., Ritter, P., Liu, H., and Häusler, K.: Average thermospheric wind patterns over the polar regions, as observed by CHAMP, Ann. Geophys., 25, 1093-1101, doi:10.5194/angeo25-1093-2007, 2007.

Lühr, H., Park, J., Ritter, P., and Liu, H.: In-situ CHAMP observation of ionospheric-thermospheric coupling, Space Sci. Rev., 168, 237-260, 2012.

Ma, T.-Z. and Schunk, R. W.: Effect of Polar Cap Patches on the Polar Thermosphere, J. Geophys. Res., 100, 19701-19713, 1995.

Moen, J., Oksavik, K., and Carlson, H. C.: On the relationship between ion upflow events and cusp auroral transients, Geophys. Res. Lett., 31, L11808, doi:10.1029/2004GL020129, 2004.

Pfaff, R., Steigies, C., Yeoman, T., Milan, S., Lester, M., Sandholt, P. E., Oksavik, K., Clemmons, J., Knudsen, D., and Burchill, J.: Combined sounding rocket and SuperDARN/EISCAT radar observations of plasma convection, shear, irregularities and other phenomena in the cusp, and boundary layer during IMF $B_{\mathrm{Z}}$ negative and $B_{\mathrm{y}}$ negative conditions, paper presented at 35 th COSPAR Scientific Assembly, Paris, 2004.

Picone, J. M., Hedin, A. E., Drob, D. P., and Aikin, A. C.: NRLMSISE-00 empirical model of the atmosphere: Statistical comparisons and scientific issues, J. Geophys. Res., 107, 1468, doi:10.1029/2002JA009430, 2002.

Prölss, G. W.: Magnetic storm associated perturbations of the upper atmosphere, in: Magnetic Storms, Geophys. Monogr. Ser., 98, 227-241, edited by: Tsurutani, B. T., Gonzalez, W. D., Kamide, Y., and Arballo, J. K., AGU, Washington, D.C., 1997.

Prölss, G. W.: Electron temperature enhancement beneath the magnetospheric cusp, J. Geophys. Res., 111, A07304, 2006.

Prölss, G. W.: Perturbations of the polar upper atmosphere in the cleft region, J. Atmos. Solar-Terr. Phys., 70, 2374-2380, 2008.

Prölss, G. W.: Density perturbations in the upper atmosphere caused by the dissipation of solar wind energy, Surv. Geophys., 32, 101195, 2011.

Reigber, Ch., Lühr, H., and Schwintzer, P.: CHAMP mission status, Adv. Space Res., 30, 129-134, 2002.

Rentz, S. and Lühr, H.: Climatology of the cusp-related thermospheric mass density anomaly, as derived from CHAMP observations, Ann. Geophys., 26, 2807-2823, doi:10.5194/angeo-262807-2008, 2008.

Rich, F. J. and Hairston, M.: Large-Scale Convection Patterns Observed by DMSP, J. Geophys. Res., 99, 3827-3844, 1994.

Richmond, A. D.: Ionospheric Electrodynamics Using Magnetic Apex Coordinates, J. Geophys. Res., 47, 191-212, 1995.

Ritter, P. and Lühr, H.: Search for magnetically quiet CHAMP polar passes and the characteristics of ionospheric currents during the dark season, Ann. Geophys., 24, 2997-3009, doi:10.5194/angeo24-2997-2006, 2006.

Ritter, P., Lühr, H., and Doornbos, E.: Substorm-related thermospheric density and wind disturbances derived from CHAMP observations, Ann. Geophys., 28, 1207-1220, doi:10.5194/angeo28-1207-2010, 2010.

Roble, R. G.: Dynamics of the Earth's thermosphere, Rev. Geophys., 21, 217-233, 1983.

Rother, M., Schlegel, K., and Lühr, H.: CHAMP observation of intense kilometer-scale field-aligned currents, evidence for an ionospheric Alfvén resonator, Ann. Geophys., 25, 1603-1615, doi:10.5194/angeo-25-1603-2007, 2007. 
Rother, M., Schlegel, K., Lühr, H., and Cooke, D.: Validation of CHAMP electron temperature measurements by incoherent scatter radar data, Radio Sci., 45, RS6020, doi:10.1029/2010RS004445, 2010.

Russell, C. T.: The polar cusp, Adv. Space Res., 25, 1413-1424, 2000.

Sadler, F. B., Lessard, M., Lund, E., Otto, A., and Lühr, H.: Auroral precipitation/ion upwelling as a driver of neutral density enhancement in the cusp, J. Atmos. Sol.-Terr. Phys., 87-88, 82-90, 2012.

Schlegel, K., Lühr, H., St.-Maurice, J.-P., Crowley, G., and Hackert, C.: Thermospheric density structures over the polar regions observed with CHAMP, Ann. Geophys., 23, 1659-1672, doi:10.5194/angeo-23-1659-2005, 2005.

Schunk, R. W. and Nagy, A. F.: Ionospheres: Physics, Plasma Physics, and Chemistry, Second ed., Cambridge Univ. Press, Cambridge, 258-265, 2009.

Strangeway, R. J., Ergun, R. E., Su, Y.-J., Carlson, C. W., and Elphic, R. C.: Factors controlling ionospheric outflows as observed at intermediate altitudes, J. Geophys. Res., 110, A03221, doi:10.1029/2004JA010829, 2005.
Tapley, B. D., Bettadpur, S., Watkins, M., and Reigber, C.: The gravity recovery and climate experiment: Mission overview and early results, Geophys. Res. Lett., 31, L09607, doi:10.1029/2004GL019920, 2004.

Wang, H., Lühr, H., and Ma, S. Y.: Solar zenith angle and merging electric field control of field-aligned currents: A statistical study of the Southern Hemisphere, J. Geophys. Res., 110, A03306, doi:10.1029/2004JA010530, 2005.

Wang, H., Lühr, H., Ritter, P., and Kervalishvili, G.: Temporal and spatial effects of Subauroral Polarization Streams on the thermospheric dynamics, J. Geophys. Res., 117, A11307, doi:10.1029/2012JA018067, 2012.

Watermann, J., Stauning, P., Lühr, H., Newell, P. T., Christiansen, F., and Schlegel, K.: Are small-scale field-aligned currents and magnetosheath-like particle precipitation signatures of the same low-altitude cusp?, Adv. Space Res., 43, 41-46, doi:10.1016/j.asr.2008.03.031, 2009. 